\title{
The Role of a Host-Induced Arginase of Xanthomonas oryzae pv. oryzae in Promoting Virulence on Rice
}

\author{
Yuqiang Zhang, ${ }^{1}$ Guichun Wu, ${ }^{2}$ Ian Palmer, ${ }^{3}$ Bo Wang, ${ }^{1}$ Guoliang Qian, ${ }^{1}$ Zheng Qing Fu, ${ }^{3}$ and Fengquan Liu ${ }^{1,2,4, \dagger}$ \\ ${ }^{1}$ Department of Plant Pathology, College of Plant Protection, Nanjing Agricultural University, and Key Laboratory of Integrated Management \\ of Crop Diseases and Pests (Nanjing Agricultural University), Ministry of Education, Nanjing 210095, P.R. China \\ ${ }^{2}$ Institute of Plant Protection, Jiangsu Academy of Agricultural Sciences, Jiangsu Key Laboratory for Food Quality and Safety, State Key \\ Laboratory Cultivation Base of Ministry of Science and Technology, Nanjing 210014, P.R. China \\ ${ }^{3}$ Department of Biological Sciences, University of South Carolina, Columbia, SC 29208, U.S.A. \\ ${ }^{4}$ School of Environment and Safety Engineering, Jiangsu University, Zhenjiang 212013, P.R. China \\ Accepted for publication 30 June 2019.
}

\begin{abstract}
The plant bacterial pathogen Xanthomonas oryzae pv. oryzae causes bacterial blight of rice, which is one of the most destructive rice diseases prevalent in Asia and parts of Africa. Despite many years of research, how $X$. oryzae pv. oryzae causes bacterial blight of rice is still not completely understood. Here, we show that the loss of the rocF gene caused a significant decrease in the virulence of $X$. oryzae pv. oryzae in the susceptible rice cultivar IR24. Bioinformatics analysis demonstrated that rocF encodes arginase. Quantitative real-time PCR and Western blot assays revealed that $r o c F$ expression was significantly induced by rice

and arginine. The $\operatorname{rocF}$ deletion mutant strain showed elevated sensitivity to hydrogen peroxide, reduced extracellular polysaccharide (EPS) production, and reduced biofilm formation, all of which are important determinants for the full virulence of $X$. oryzae pv. oryzae, compared with the wild-type strain. Taken together, the results of this study revealed a mechanism by which a bacterial arginase is required for the full virulence of $X$. oryzae pv. oryzae on rice because of its contribution to tolerance to reactive oxygen species, EPS production, and biofilm formation.
\end{abstract}

The plant bacterial pathogen Xanthomonas oryzae pv. oryzae causes bacterial blight of rice, which was first characterized in Japan in 1884 and is one of the most destructive rice diseases prevalent in Asia and parts of Africa, Australia, and Latin America (Niño-Liu et al. 2006; Sere et al. 2005). X. oryzae pv. oryzae typically infects rice leaves through wound sites or hydathodes at the leaf tip or margin. After the pathogen propagates in the intercellular spaces of the epidermis, the bacteria colonize and spread through the plant xylem vessels where they can interact with the xylem parenchyma cells, ultimately resulting in tissue necrosis and wilting (González et al. 2012).

The $X$. oryzae pv. oryzae-rice interaction is an important working model to explain how pathogens inhibit host plant immune responses (Hilaire et al. 2001). Previous studies indicate that $X$. oryzae pv. oryzae can employ multiple virulence factors to promote its pathogenicity on rice, such as extracellular polysaccharide (EPS), biofilm, effectors secreted by the type III secretion system, cell motility, adhesion molecules, stress tolerance, and the quorum sensing (QS) system (Büttner and Bonas 2010; Yu et al. 2016). EPSs can enhance the attachment to different environmental surfaces, protect themselves from desiccation, and promote the colonization of bacterial pathogens in the host by reducing host responses (Sutherland 1988). EPS is also involved in the formation of biofilm (Vu et al. 2009). Biofilm is an important

†Corresponding author: F. Liu; fqliu20011@sina.com

Funding: This work was supported by the National Natural Science Foundation of China (grants 31571974 and 31371906 ).

Y. Zhang and G. Wu contributed equally to this work.

*The e-Xtra logo stands for "electronic extra" and indicates that three supplementary figures and one supplementary table are published online.

The author(s) declare no conflict of interest.

(c) 2019 The American Phytopathological Society virulence factor for bacterial pathogens to protect themselves from environment stresses such as superoxide radicals, hydrogen peroxide $\left(\mathrm{H}_{2} \mathrm{O}_{2}\right)$, and high or low $\mathrm{pH}$ values (Marquis 1995). EPS production and biofilm formation are critical for tolerance to $\mathrm{H}_{2} \mathrm{O}_{2}$, which is an antimicrobial agent used to kill $X$. oryzae pv. oryzae (Bae et al. 2018). In addition, EPS production and biofilm formation in bacteria can be regulated by QS (Von Bodman et al. 1998).

Studies have shown that arginine can augment biofilm formation and polysaccharide intercellular adhesion to promote the pathogenic ability of Staphylococcus aureus (Zhu et al. 2007). In addition, arginine is important for the growth and biofilm development of Streptococcus gordonii, which is an oral bacterium (Jakubovics et al. 2015). The arginase pathway is one arm of arginine catabolism in bacterial pathogens that is encoded by the roc $A B C$ and rocDEF operons and the roc $G$ gene (Calogero et al. 1994; Gardan et al. 1995). The rocF gene that encodes arginase is responsible for the first step of the arginase pathway, which hydrolyzes arginine to ornithine and urea (Lu 2006). Arginase was shown to be crucial for its pathogenicity of Helicobacter pylori in the human stomach through dysregulation of the host immune response, such as by inhibiting nitric oxide (NO) production of macrophages by directly competing with host nitric oxide synthase (NOS), protecting pathogens from reactive oxygen species (ROS) damage, inhibiting human T-cell proliferation, and reducing T-cell receptor (TCR)-zeta chain (CD3 zeta) expression (George et al. 2017; Gobert et al. 2001; Shi et al. 2014; Zabaleta et al. 2004). In addition, arginase is essential for Leishmania donovani survival in humans to cause disease (Boitz et al. 2017). This pathway is also employed by some pathogens to consume arginine as a carbon and nitrogen source during their infection of the host, which has been shown in Mycobacterium tuberculosis, Trypanosoma cruzi, and Candida albicans (Xiong et al. 2016).

Interestingly, our preliminary study of proteomics showed that RocF expression in $X$. oryzae pv. oryzae was induced by host rice and was identified as arginase. Yet the reason why it was induced is still unknown. Pathogenic bacteria can activate the transcription of 
host-induced genes to disrupt host immune response and adapt to highly heterogenous environments in host tissues (Bumann and Valdivia 2007). A study by Brown et al. (2007) indicated that the expression of genes acrA and $\operatorname{din} F$ in Ralstonia solanacearum can be induced by toxic compounds, and these genes are required for colonization and bacterial wilt virulence in tomato. Using twodimensional polyacrylamide gel electrophoresis, Kachroo et al. (1997) found that there is one rice-induced protein in Magnaporthe grisea that plays an important role in the process of infection. In addition, studies demonstrated that sRNA genes are related to the adaptation to environmental stress conditions and the pathogenicity of bacterial pathogens. For example, the expression of sRNA IsrJ, which controls the virulence of Salmonella typhimurium by regulating the translocation efficiency of virulence-associated effectors into host cells, was induced by low oxygen or magnesium within macrophages (Padalon-Brauch et al. 2008). Therefore, the hostinduced genes, protein, and sRNA are required for pathogen virulence. Whether the rice-induced arginase in $X$. oryzae pv. oryzae is also important for promoting virulence on rice is still undetermined.

In this study, we found that arginase is encoded by $\operatorname{rocF}$ (accession WP_011407409) and is required for the full virulence of $X$. oryzae pv. oryzae on rice. Bioinformatic analysis showed that rocF is highly conserved among important plant-pathogenic Xanthomonas species. Using quantitative real-time (qRT)-PCR and Western blot analysis, we also obtained evidence showing that roc $F$ expression is significantly induced by rice leaf extracts and arginine. Subsequent genetic and phenotypic studies showed that rocF plays an important role in the multiple virulence-related functions of $X$. oryzae pv. oryzae, including EPS production, biofilm formation, and $\mathrm{H}_{2} \mathrm{O}_{2}$ tolerance. To our knowledge, this is the first report of a bacterial arginase that is a functional virulence factor in a plant pathogen, and these findings will be useful in elucidating the course of events in plant-pathogen interactions.

\section{MATERIALS AND METHODS}

Strains, plasmids, and growth conditions. The bacterial strains and plasmids used in this study are listed in Table 1. Escherichia coli was grown in Luria-Bertani medium at $37^{\circ} \mathrm{C}$ and the $X$. oryzae pv. oryzae wild-type strain PXO99A and derived mutant strains were cultured in nutrient broth (NB) medium at $28^{\circ} \mathrm{C}$ (Qian et al. 2013). Minimal medium XVM1 (20 mM of $\mathrm{NaCl}$, $0.5 \mathrm{mM}$ of phosphate, $10 \mathrm{mM}$ of sucrose, and $2 \mathrm{mg}$ of methionine/ liter) contained macerated rice, wheat, or tobacco leaves: $20 \mathrm{~g}$ of
4- to 5-week-old leaves of rice, wheat, or tobacco was macerated in liquid nitrogen and used as leaf extract, which was then added to $400 \mathrm{ml}$ of XVM1 medium and autoclaved to analyze rocF expression (González et al. 2013; Tsuge et al. 2002). Antibiotics kanamycin $(50 \mu \mathrm{g} / \mathrm{ml})$, spectinomycin $(25 \mu \mathrm{g} / \mathrm{ml})$, and gentamicin $(25 \mu \mathrm{g} / \mathrm{ml})$ were added to the growth medium as appropriate for selection. Plasmids were transformed into $E$. coli by heat shock and into the $X$. oryzae pv. oryzae wild-type strain PXO99A by electroporation.

Bioinformatic analysis of the RocF protein. The domain organization of RocF was analyzed using SMART online software (http://smart.embl-heidelberg.de/). BLASTP was used to search for homologs of RocF in Xanthomonas species that were obtained from NCBI. DNAMAN software was used to analyze the relevant DNA sequence alignments.

Construction of the $\operatorname{rocF}$ gene deletion mutant and complementary strains. $X$. oryzae pv. oryzae wild-type strain PXO99A was used as the parental strain to obtain the in-frame deletion mutant via a previously described allelic homologous recombination method (Qian et al. 2013). For complementation of $r o c F$, an 1,890-bp DNA fragment containing $r o c F$ and its predicted promoter region was cloned into pUFR047 plasmid. The resulting constructs were transformed into the $\Delta \operatorname{roc} F$ strain by electroporation to obtain the complementary strain. The PCR primers used in this study are listed in Supplementary Table S1.

Construction of pSS122 promoter-probe plasmid and $\boldsymbol{\beta}$-glucuronidase reporter assay. To determine $r o c F$ promoter activity, the $\operatorname{roc} F$ promoter was predicted using Promoter 2.0 Prediction Server online software (http://www.fruitfly.org/seq tools/promoter.html) and one 376-bp promoter was amplified by PCR using the forward and reverse primers $\mathrm{P}-r o c F-\mathrm{F}$ and $\mathrm{P}-r o c F-\mathrm{R}$, respectively. The amplified promoter was digested with restriction endonucleases and was then integrated into the pSS122 promoterprobe vector plasmid (which was constructed from pUFR047) by $\mathrm{T}_{4}$ DNA ligase. The recombined plasmid was then transformed into the wild-type strain by electroporation and grown on NB agar plates with gentamicin and ampicillin. In addition, the $\beta$-glucuronidase activity assay was performed as described (Pandey and Sonti 2010). Briefly, a single colony was cultured in NB liquid medium with gentamicin and ampicillin to an optical density of 1.0 at $600 \mathrm{~nm}$, and 3- $\mu$ l bacterial suspensions were dropped onto XVM1 medium plates containing $38 \mu \mathrm{M}$ of 5-bromo-4-chloro-3-indolyl- $\beta$-Dglucuronic acid (X-Gluc)/ml and different concentrations of arginine at $28^{\circ} \mathrm{C}$ for 5 to 7 days. At the same time, 4- to 5-weekold leaves from the susceptible rice cultivar IR24 were inoculated

TABLE 1. Bacterial strains and plasmids used in this study

\begin{tabular}{|c|c|c|}
\hline Strain & Characteristics $^{\mathrm{z}}$ & Reference \\
\hline \multicolumn{3}{|l|}{ Escherichia coli } \\
\hline DH5a & $\begin{array}{l}F-, \varphi 80 d l a c Z \Delta M 15, \Delta(\text { lacZYA-argF }) U 169, \text { deoR, recA1, endA1, hsdR17(rk-,mk+), } \\
\text { phoA, supE44, } \lambda-\text {, thi-1, gyrA96 }\end{array}$ & This study \\
\hline PXO99A & Philippine race 6; wild-type strain & Qian et al. (2013) \\
\hline$\Delta r o c F$ & rocF in-frame deletion mutant of strain $\mathrm{PXO} 99^{\mathrm{A}}$ & This study \\
\hline$\Delta r o c F(r o c F)$ & $\Delta r o c F$ harboring plasmid pUFR047-rocF (complementary strain); $\mathrm{Gm}^{\mathrm{R}}, \mathrm{Amp}^{\mathrm{R}}$ & This study \\
\hline PXO99A(pUFZ75) & PXO99A harboring plasmid pUFZ75 (GFP-labeled strain); $\mathrm{Km}^{\mathrm{R}}$ & This study \\
\hline PXO99A (pSS122::rocF) & $\mathrm{PXO}^{\mathrm{A}}$ harboring plasmid pSS122 with rocF promotor; $\mathrm{Ap}^{\mathrm{R}}, \mathrm{Gm}^{\mathrm{R}}$ & This study \\
\hline \multicolumn{3}{|c|}{$e^{2}$} \\
\hline pK18mobsacB & Allelic exchange suicide vector, $s a c B$ oriT(RP4); $\mathrm{Km}^{\mathrm{R}}$ & Qian et al. (2013) \\
\hline pK18-rocF & pK18mobsacB with two rocF flanking fragments; $\mathrm{Km}^{\mathrm{R}}$ & This study \\
\hline pUFR047 & Broad-host-range expression vector; $\mathrm{IncW}, \mathrm{Gm}^{\mathrm{R}}, \mathrm{Amp}^{\mathrm{R}}, \mathrm{Mob}^{+}, \mathrm{Mob}(\mathrm{p}), \mathrm{lacZ} \alpha^{+}, \mathrm{Par}^{+}$ & Andrade et al. (2014) \\
\hline pUFR047-rocF & pUFR047 carrying gene rocF with its native promoter region; $\mathrm{Gm}^{\mathrm{R}}, \mathrm{Amp}^{\mathrm{R}}$ & This study \\
\hline pUFR047-rocF-Flag & pUFR047 carrying gene $r o c F$ with its native promoter region and Flag label; $\mathrm{Gm}^{\mathrm{R}}$, Amp $\mathrm{R}$ & This study \\
\hline
\end{tabular}

${ }^{\mathrm{z}} \mathrm{Gm}^{\mathrm{R}}=$ gentamicin, $\mathrm{Amp}^{\mathrm{R}}=$ ampicillin, $\mathrm{GFP}=$ green fluorescent protein, and $\mathrm{Km}^{\mathrm{R}}=$ kanamycin. 
with the wild-type strain, which contained the pSS122 plasmid with or without the roc $F$ promoter produced using the leaf-clipping method. Then the leaves from days 7 and 14 were dipped into $\beta$-glucuronidase (GUS) assay buffer containing $38 \mu \mathrm{M}$ of X-Gluc/ $\mathrm{ml}$ at $37^{\circ} \mathrm{C}$ for 3 days. All of the leaves were subsequently dipped into ethanol for approximately $5 \mathrm{~min}$, which was repeated three times until the chlorophyll in the rice leaves disappeared. Leaves that were inoculated with $\mathrm{ddH}_{2} \mathrm{O}$ and the wild-type strain served as a negative control. At least 20 leaves were inoculated for each treatment and every treatment was repeated three times.

RNA extraction and qRT-PCR analysis. Transcription levels of genes in the PXO99A strains that were cultured in NB liquid medium with or without $\mathrm{H}_{2} \mathrm{O}_{2}$ and XVM1 liquid medium with or without rice, wheat, or tobacco leaf extracts or $0.1 \mathrm{mM}$ of amino acids were analyzed as described with some modifications (Song et al. 2017). Total RNA was extracted with TRIzol reagent (Takara, Dalian, China) according to the manufacturer's protocol. cDNA was synthesized from total RNA using the TransScript Allin-One First-Strand cDNA Synthesis SuperMix kit (with One-Step gDNA Removal) (TransGen Biotech, Beijing, China) according to the manufacturer's instructions. qRT-PCR was performed in the QuantStudio 6 and 7 Flex Real-Time PCR System (Applied Biosystems, Foster City, CA). One-hundred nanograms of cDNA of each sample was used in qRT-PCR. The relative expression ratio was calculated using the $\Delta \Delta$ threshold cycle method. $16 \mathrm{~S}$ rRNA was used as an endogenous control and qRT-PCR was repeated three times with four independent biological replicates each time.

Western blot analysis of RocF protein expression. To test the RocF protein expression level under different conditions, one integrated PXO99A strain was cultured as previously described (Wang et al. 2018). Briefly, we fused the Flag tag (GAT TAC AAG GAT GAC GAC GAT AAG) to the $5^{\prime}$ terminus of rocF and this fragment was amplified by PCR. Then the fragment was cloned into the pUFR047 plasmid and the integrated plasmid was transformed into $X$. oryzae pv. oryzae wild-type strain PXO99A to obtain a strain in which the region containing $\operatorname{rocF}$ was replaced by the FLAGtagged fused fragment. The integrated PXO99A $X$. oryzae pv. oryzae wild-type strains were cultured in $50 \mathrm{ml}$ of NB liquid medium at $28^{\circ} \mathrm{C}$ while shaking at $220 \mathrm{rpm}$ to an optical density of 1.0 at $600 \mathrm{~nm}$ and were centrifuged at $6,000 \mathrm{rpm}$ for $5 \mathrm{~min}$. Then the supernatants were discarded and the cell pellets were suspended in $50 \mathrm{ml}$ of XVM1 liquid medium with or without rice, wheat, or tobacco leaf extracts or $0.1 \mathrm{mM}$ of arginine at $28^{\circ} \mathrm{C}$ while shaking at $220 \mathrm{rpm}$ for another 16-h incubation. Bacterial cells were harvested at $10,000 \mathrm{rpm}$ at $4^{\circ} \mathrm{C}$ for $10 \mathrm{~min}$, and $1 \mathrm{ml}$ of radioimmunoprecipitation assay lysis buffer with $3 \mu$ l of phenylmethanesulfonyl fluoride and $3 \mu \mathrm{l}$ of protease inhibitor cocktail was added to extract the total proteins. The samples were subsequently centrifuged at $10,000 \mathrm{rpm}$ at $4{ }^{\circ} \mathrm{C}$ for $5 \mathrm{~min}$ and the supernatants were transferred to new 2-ml tubes containing protein loading buffer before they were frozen at $-80^{\circ} \mathrm{C}$. Six micrograms of total proteins of each sample was used in Western blot analysis. Soluble proteins were separated on SDS-PAGE and transferred onto polyvinylidene difluoride membranes using a semidry blot machine (Bio-Rad). Membranes were blocked with $1 \times$ phosphate-buffered saline with Tween with $5 \%$ nonfat milk and were probed with anti-Flag mouse antibody $(1: 5,000)$ before they were incubated with horseradish peroxidaseconjugated goat antimouse secondary antibody $(1: 10,000)$. The $\alpha$ subunit of RNA polymerase was used as a control for sample loading. The experiment was independently repeated three times.

Virulence assays on rice. The susceptible rice cultivar IR24 was planted in a growth chamber under a cycle of $16 \mathrm{~h}$ of light at $28^{\circ} \mathrm{C}$ and $8 \mathrm{~h}$ of darkness at $25^{\circ} \mathrm{C}$, and then the 4 - to 5 -week-old leaves were inoculated with PXO99A strains in sterile distilled water at an optical density of 0.5 at $600 \mathrm{~nm}$ by the leaf-clipping method described previously (Wang et al. 2018). Lesion lengths were measured 15 days postinoculation. For the bacterial population assay, 3-cm clipped leaf sections were centered on the sites that were inoculated by PXO99A strains and were ground in a 2-ml tube with $1 \mathrm{ml}$ of sterile distilled water; at least 10 leaves were collected for each sample. Bacterial populations were measured by dilution plating of $100 \mu \mathrm{l}$ of bacterial suspension on NB solid medium and the number of bacterial colonies was counted. At least 50 leaves were inoculated by each treatment and every treatment was repeated three times.

Biofilm formation assays. The method used to analyze biofilm formation was described previously with some modifications ( $\mathrm{Li}$ and Wang 2012). Briefly, the PXO99A strains were cultured in NB liquid medium to an optical density of 1.0 at $600 \mathrm{~nm}$. Forty-microliter bacterial suspensions were transferred to sterilized polystyrene tubes with $4 \mathrm{ml}$ of NB liquid medium and incubated at $28^{\circ} \mathrm{C}$ while shaking at $220 \mathrm{rpm}$ overnight. All of the tubes were subsequently kept in the chamber at $28^{\circ} \mathrm{C}$ for 7 days without shaking. The bacterial suspensions were moved from the tubes and washed three times with sterilized water. Biofilm formed on the tubes was visualized by staining with $0.1 \%$ crystal violet; after $20 \mathrm{~min}$, excess stain was removed and the tubes were washed three times with sterilized water. The stained biofilm on the tubes was dissolved in acetic acid/ethanol (1:4, vol/vol) and the absorbance value was measured at an optical density of $590 \mathrm{~nm}$ through the use of an Agilent 8453 ultraviolet-visible spectrophotometer (Agilent Technologies Inc., Santa Clara, CA). The experiment was repeated three times.

The confocal laser scanning microscopy (CLSM) technology used to assay biofilm formation was described previously (Tondo et al. 2016). In brief, we transformed the pUFZ75 plasmid, which can express green fluorescent protein (GFP), into the PXO99A strains. The GFP-labeled PXO99A strains were cultured in NB liquid medium with $10 \mathrm{mM}$ of kanamycin to an optical density of 1.0 at $600 \mathrm{~nm} ; 40-\mu \mathrm{l}$ suspensions were transferred into $4 \mathrm{ml}$ of NB liquid medium, and then $200-\mu \mathrm{l}$ mixed suspensions were transferred into sterilized flow chambers covered with glass slides (catalog number 155411; Lab-Tek/NUNC, Naperville, IL). All of the flow chambers were kept in a humidified polyvinylchloride box at $28^{\circ} \mathrm{C}$ for 2 to 3 days without shaking. Biofilm construction was visualized by CLSM (Leica Microsystems Inc., Buffalo Grove, IL) with an excitation wavelength of $488 \mathrm{~nm}$ and an emission wavelength of 500 to $545 \mathrm{~nm}$ with a $20 \times$ objective. The images were analyzed with LAS_X_Small_2.0.0_14332 software, which was provided with the confocal microscope described above. At least three biological replicates were carried out for each treatment.

Measurement of tolerance to oxidative stresses. The PXO99A strains were cultured in NB liquid medium and grown to an optical density of 1.0 at $600 \mathrm{~nm}$. Then $80-\mu \mathrm{l}$ bacterial suspensions of each strain were transferred into new sterilized glass bottles with $8 \mathrm{ml}$ of NB liquid medium containing $0,0.1$, and $0.2 \mathrm{mM}$ of $\mathrm{H}_{2} \mathrm{O}_{2}$. At the same time, bacterial suspensions of the PXO99A strains at an optical density of 1.0 at $600 \mathrm{~nm}$ were diluted 5-fold $(5 \times)$ and 25 -fold $(25 x)$ and 3- $\mu$ l diluted bacterial suspensions were dropped onto the surface of NB solid plates with $0,0.1$, and $0.2 \mathrm{mM}$ of $\mathrm{H}_{2} \mathrm{O}_{2}$. All glass bottles were inoculated at $28^{\circ} \mathrm{C}$ while rotating at a speed of $220 \mathrm{rpm}$ and the plates were inoculated in a $28^{\circ} \mathrm{C}$ incubator for 2 to 3 days. Bacterial viability was analyzed by observing their growth on these plates and in these bottles. At least three biological replicates were carried out for each treatment.

Quantitative determination of EPS production. The PXO99A strains were cultured on NB agar plates at $28^{\circ} \mathrm{C}$ for 2 to 3 days. Cells were then incubated in NB liquid medium at $220 \mathrm{rpm}$ at $28^{\circ} \mathrm{C}$ to an optical density of 1.0 at $600 \mathrm{~nm}$. Then $500-\mu l$ bacterial suspensions of the relative strains were transferred to $50 \mathrm{ml}$ of sterilized NB liquid medium and incubated at $28^{\circ} \mathrm{C}$ with constant shaking at $220 \mathrm{rpm}$ for 5 days. A $50-\mathrm{ml}$ bacterial suspension was centrifuged at $10,000 \mathrm{rpm}$ for $10 \mathrm{~min}$, the supernatant was transformed into new containers, and $100 \mathrm{ml}$ of ethanol was added to precipitate the EPS for $24 \mathrm{~h}$. The precipitated EPS was then dried 
at $70^{\circ} \mathrm{C}$ and the dried EPS was weighed using a digital analytical balance. Every experiment was repeated at least three times.

Data analysis. All analysis was conducted using SPSS 14.0 software (SPSS Inc., Chicago, IL). Significant differences in virulence, bacterial population, EPS production, biofilm formation, and gene expression among different strains were determined via the hypothesis test of percentages ( $t$ test).

\section{RESULTS}

RocF protein is highly conserved among many important plant-pathogenic Xanthomonas species. To better understand $r o c F$, bioinformatics analysis was performed. The $r o c F$ open reading frame (locus tag: $P X O \_R S 22625$ ) was $924 \mathrm{bp}$ and the nucleotide position in the genome was from 4,951,804 to 4,952,727 (Fig. 1A). The RocF protein contained arginase domain (from residues 6 to 300) that was predicted by using SMART (http:// smart.embl-heidelberg.de/); the molecular weight was $3.316 \mathrm{kDa}$, as predicted by using the ExPASy ProtParam tool (https:// web.expasy.org/protparam/). Amino acid sequence alignment analysis demonstrated that RocF was highly conserved among the important plant-pathogenic Xanthomonas species, such as $X$. oryzae pv. oryzae KACC 10331(accession AAW73689), $X$. campestris pv. campestris strain B100 (accession WP 012439504), X. campestris pv. campestris strain ATCC 33913

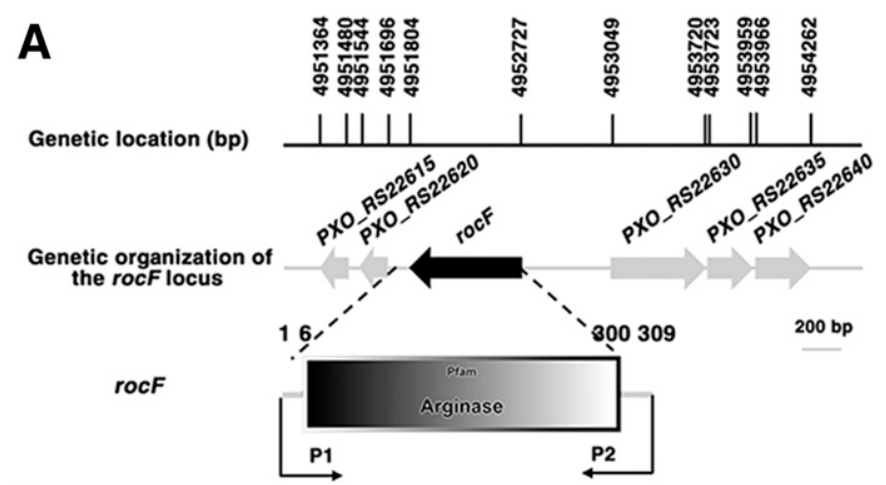

B

\begin{tabular}{|c|c|c|c|c|c|}
\hline \multirow{2}{*}{ Strain ${ }^{a}$} & \multicolumn{5}{|c|}{ Homologue } \\
\hline & Gene & Production & Size (aa) & Predicted domain ${ }^{\circ}$ & Identity (\%) \\
\hline Xoo PX099^ & rocF & arginase & 307 & Arginase & 100 \\
\hline $\begin{array}{c}\text { Xoo } \\
\text { KACC } 10331\end{array}$ & $\begin{array}{c}\text { XOO_RS } \\
02055\end{array}$ & arginase & 337 & Arginase & 100 \\
\hline X00 PX086 & AZ54_22840 & arginase & 307 & Arginase & 100 \\
\hline Xoc BLS256 & rocF & arginase & 307 & Arginase & 99.35 \\
\hline Xcc B100 & $\underset{4113}{x c c b 100}$ & arginase & 307 & Arginase & 99 \\
\hline$\underset{\text { gardneri }}{\text { Xanthomonas }}$ & $\underset{02620}{B 1317 \text { RS }}$ & arginase & 307 & Arginase & 96.74 \\
\hline$X c c 8004$ & $x C_{-} 4025$ & arginase & 307 & Arginase & 96.09 \\
\hline $\begin{array}{c}X c c \\
\text { ATCC } 33913\end{array}$ & argl & arginase & 307 & Arginase & 96 \\
\hline
\end{tabular}

Fig. 1. Bioinformatics analysis of the $\operatorname{rocF}$ gene. A, Schematic diagram of rocF in the genome of Xanthomonas oryzae pv. oryzae PXO99 A Open arrows indicate the location, length, and orientation of the open reading frames. The middle element shows the domain structure analysis of the RocF protein, which was performed using SMART online software (http://smart.embl-hei delberg.de/). The lower element shows that $r o c F$ was amplified by PCR primers P1 and P2 and was cloned into the pUFR047 plasmid for complementation of the $\operatorname{roc} F$ deletion mutant. B, The identity of arginase homologs in important plant-pathogenic Xanthomonas species. ${ }^{a} X o o=X$. oryzae pv. oryzae, $X o c=X$. oryzae pv. oryzicola, and Xcc $=X$. campestris pv. campestris. ${ }^{b}$ Domains were predicted by SMART. ${ }^{\mathrm{c} A c c o r d i n g}$ to a BLASTP search. (accession NP_639266), X. oryzae pv. oryzicola BLS256 (accession AEQ98376), X. campestris pv. campestris strain 8004 (accession AAY51054), X. gardneri (accession WP_074058724), and X. oryzae pv. oryzae PXO86 (accession AJQ85091) (Fig. 1B).

roc $F$ expression is induced by rice leaf extracts and arginine in vitro. To determine whether $\operatorname{roc} F$ expression can be induced by rice leaf extracts, we performed qRT-PCR experiments to determine the $r o c F$ transcription level in XVM1 liquid medium with or without rice leaf extracts as described in the Materials and Methods. The qRT-PCR results showed that the rocF transcription level was approximately 4-fold higher in XVM1 medium in the presence of rice leaf extracts than in XVM1 medium; the rocF transcription level could also be significantly induced by nonhost plant leaf extracts, including wheat and tobacco. The same method was used to detect the $r o c F$ transcription level in XVM1 liquid medium with $0.1 \mathrm{mM}$ of arginine. The qRT-PCR results showed that the $\operatorname{roc} F$ transcription level was approximately 5-fold higher in XVM1 medium in the presence of $0.1 \mathrm{mM}$ of arginine than in XVM1 medium in the absence of arginine (Fig. 2A). We also
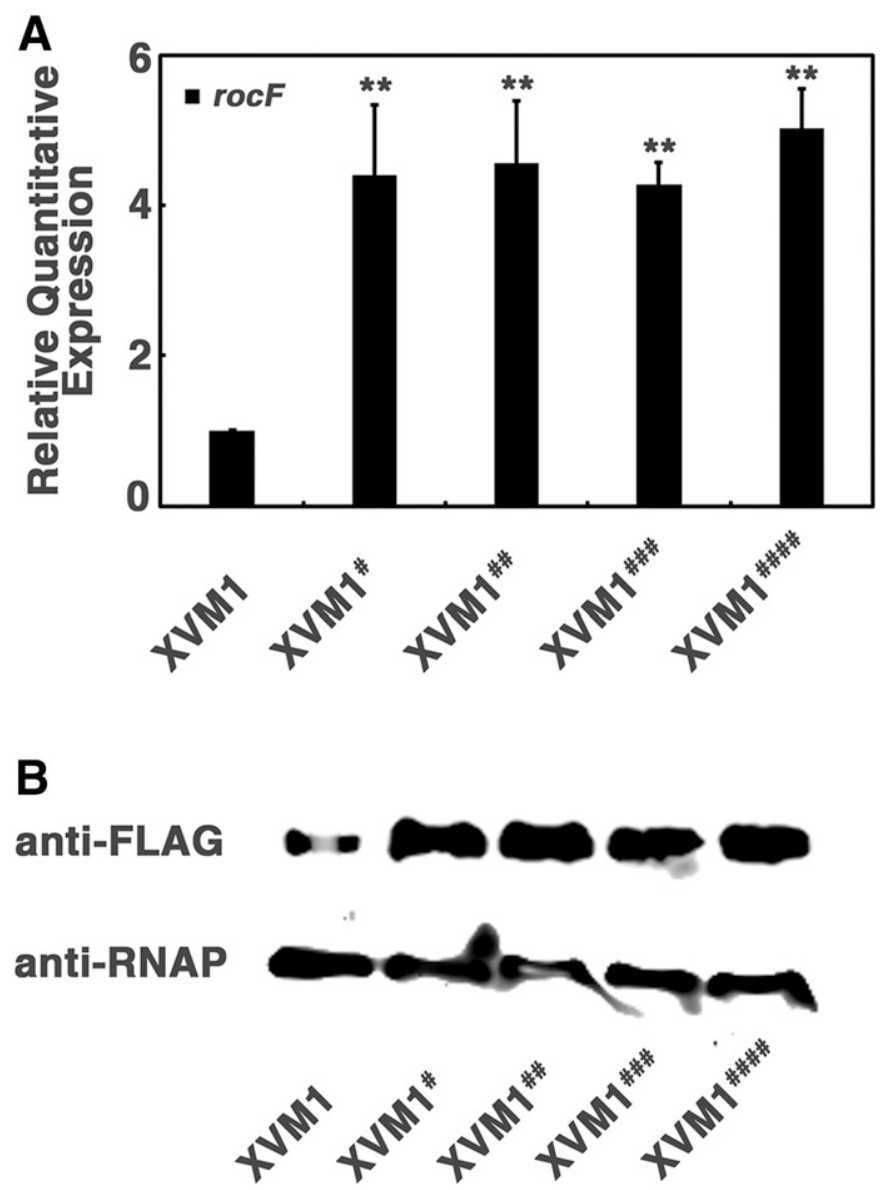

Fig. 2. $r o c F$ expression in different media. A, mRNA expression levels of rocF in different XVM1 media were detected using quantitative real-time (qRT)PCR. Relative transcription levels of these genes were calculated by qRT-PCR with respect to the corresponding transcription levels in the wild type and the $16 \mathrm{~S}$ rRNA as the internal standard. B, Analysis of RocF protein expression levels in different XVM1 media using Western blot analysis. The upper bands corresponding to the predicted size of RocF-FLAG fusion were detected by the monoclonal antibody. Anti-FLAG and the lower bands corresponding to the RNA polymerase $\alpha$-subunit were detected by the specific antibody anti-RNAP. Values are the means \pm SD from three independent experiments. Asterisks above the error bars indicate significant differences compared with XVM1 medium $\left(t\right.$ test, $\left.{ }^{* *} P<0.01\right)$. XVM1 = negative control, $X V M 11^{\#}=X V M 1$ with $0.1 \mathrm{mM}$ of arginine/liter, $\mathrm{XVM} 1^{\# \#}=\mathrm{XVM} 1$ with $5 \mathrm{~g}$ of rice leaf extract/liter, $\mathrm{XVM} 1^{\# \# \#}=\mathrm{XVM} 1$ with $5 \mathrm{~g}$ of wheat leaf extract/liter, and XVM1 \#\#\#\# = XVM1 with $5 \mathrm{~g}$ of tobacco leaf extract/liter. 
measured the rocF transcription level in XVM1 medium containing seven different amino acids at a concentration of $0.1 \mathrm{mM}$. The results showed that $r o c F$ expression was significantly induced by glutamate and ornithine, which were metabolites from arginine, but not by histidine, methionine, proline, phenylalanine, and leucine (Supplementary Fig. S1). These results indicate that rocF expression can be significantly induced by rice leaf extracts and arginine.

Because $r o c F$ expression can be significantly induced by rice leaf extracts and arginine at the transcription level, we then investigated whether RocF protein expression can be induced at the same conditions by using Western blot. The integrated PXO99A strain was constructed in which the 5 '-terminus of $r o c F$ was labeled with a FLAG tag as described in the Materials and Methods. The PXO99A strain with FLAG-tagged $r o c F$ was cultured in $50 \mathrm{ml}$ of XVM1 liquid medium with or without rice leaf extracts or $0.1 \mathrm{mM}$ of arginine, and the total proteins were extracted and analyzed as described in the Materials and Methods. Western blot analysis showed that the presence of rice leaf extracts or arginine resulted in a significant increase in RocF expression compared with that observed in cells grown in XVM1 medium, and detectable bands corresponding to the predicted size of the RocF-FLAG fusion protein were observed. At the same time, RocF protein expression was also significantly induced by wheat and tobacco leaf extracts. Under the same test conditions, expression of the $\alpha$ subunit of RNA polymerase was analyzed as an internal control (Fig. 2B). These data indicate that the expression of $r o c F$ and RocF can be induced by host and nonhost leaf extracts and arginine maybe the potential inducer.

Promoter activity of $\operatorname{roc} F$ is induced by arginine during pathogen infection. To further confirm that the rocF promoter was also functional in rice leaves, $\beta$-glucuronidase activity of the PXO99A strains with or without the pSS122 plasmid containing the roc $F$ promoter in rice leaves was determined as described in the Materials and Methods. Very light indigo-blue staining was observed in major longitudinal veins of rice leaves 7 days postinoculation of the PXO99A strain with the pSS122 plasmid containing the rocF promoter, but no staining was observed in major longitudinal veins of rice leaves that were infected by the PXO99A strains with or without the pSS122 reporter plasmid. Staining intensity increased during the development of rice. Intense indigo-blue staining was observed in major longitudinal veins of rice leaves 14 days postinoculation of the PXO99A strain with the pSS122 plasmid containing the rocF promoter, but indigo-blue staining still could not be observed in major longitudinal veins of rice leaves (Fig. 3A). These results demonstrate that $r o c F$ promoter activity may be increased by components of the rice leaves during the infection of the PXO99A strain.

qRT-PCR and Western blot results showed that rocF expression was significantly induced by arginine; therefore, we speculated that the arginine in rice leaves is the component to increase $r o c F$ activity. Therefore, we determined rocF activity on XVM1 medium plates with or without $0.1 \mathrm{mM}$ of arginine. Indigo staining was observed for the PXO99A strain with the pSS122 plasmid containing the rocF promoter, whereas no staining was observed for the PXO99A strain with or without the pSS122 plasmid (Fig. 3B). These results suggest that activity of the $\operatorname{roc} F$ promoter is significantly induced by arginine during pathogen infection.

rocF is required for the full virulence of $X$. oryzae $\mathrm{pv}$. oryzae. A roc $F$ deletion mutant strain and a complementary strain, $\triangle \operatorname{roc} F$ and $\Delta \operatorname{roc} F(\operatorname{roc} F)$, respectively, were constructed to investigate the potential biological functions of rocF in PXO99A. The qRT-PCR results showed that the corresponding region of rocF was deleted successfully (Supplementary Fig. S2). The virulence assay for PXO99A strains in the susceptible rice cultivar IR24 was performed by the leaf-clipping method (Guo et al. 2015). Lesion lengths were measured 15 days postinoculation (Fig. 4A) and the data are presented in Figure 4B. The wild-type strain caused a lesion length of $26 \pm 0.8 \mathrm{~cm}$, whereas the $\Delta r o c F$ strain caused a lesion length of just $12.5 \pm 1.0 \mathrm{~cm}$ in all infected leaves. These data indicate that the virulence of PXO99A is significantly decreased after deletion of $r o c F$. The virulence of the $\Delta r o c F$ strain in the leaves of susceptible rice cultivar IR24 was restored in the complementary strain $\Delta \operatorname{roc} F(\operatorname{roc} F)$, which caused a lesion length of $23 \pm 1.2 \mathrm{~cm}$. At the same time, we assayed the colonization of PXO99A on rice leaves at 0,8 , and 15 days postinoculation. Growth of the $\Delta r o c F$ strain was significantly reduced on rice leaves compared with the growth of the wild-type strain and the reduced bacterial population was restored to wild-type levels by complementation (Fig. 4C). To determine whether deletion of $r o c F$ resulted in a decrease in the proliferation of PXO99A, we tested their growth rates in NB liquid medium. There was no difference among the wild-type, $\Delta r o c F$, and $\Delta \operatorname{roc} F(r o c F)$ strains in their ability to grow in NB liquid medium (Supplementary Fig. S3). These results indicate that deletion of rocF does not influence the viability of PXO99A. Three replicates were used for each treatment and the experiment was repeated three times. Overall, these results demonstrate that a functional rocF is required for PXO99A to achieve full virulence on rice.

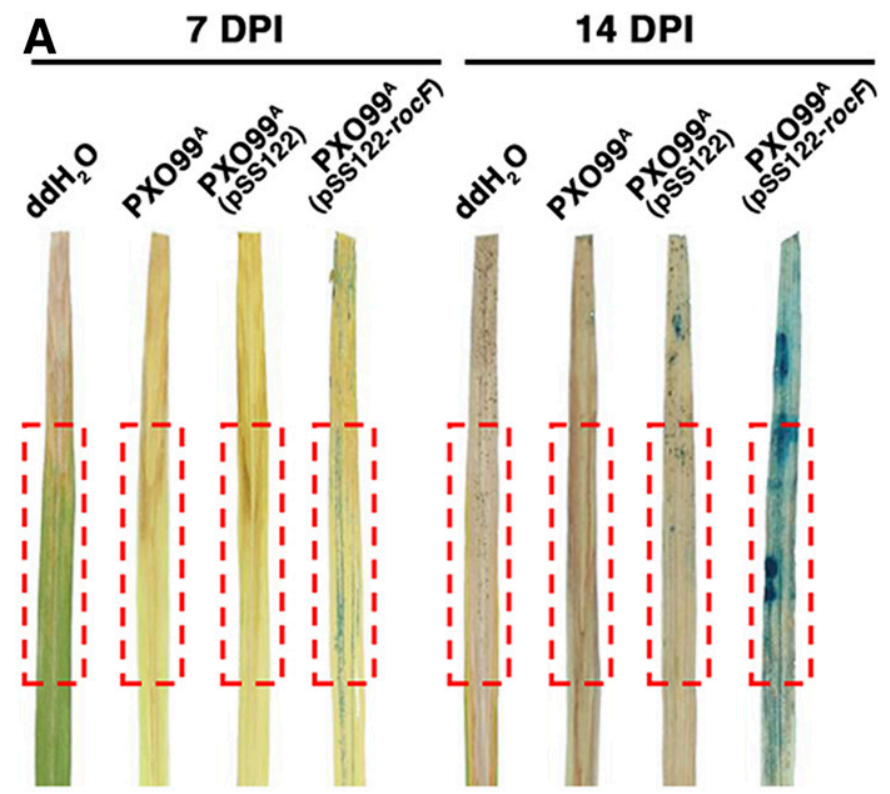

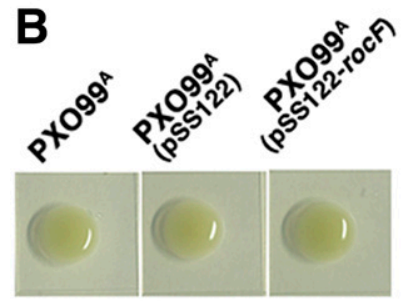

XVM1

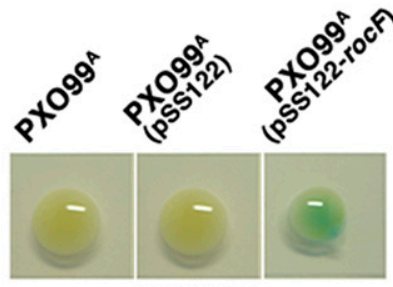

XVM1"
Fig. 3. GUS activity determination of the $r o c F$ promoter in rice leaves and under arginine conditions. A, GUS activity determination of the PXO99A strains with or without the pSS122 plasmid containing the rocF promoterinfected rice leaves stained by GUS assay buffer containing 5-bromo-4-chloro3 -indolyl- $\beta$-D-glucuronic acid (X-Gluc). The leaves were acquired 7 and 14 days postinoculation (DPI). The wild-type strain without the pSS122 vector and $\mathrm{ddH}_{2} \mathrm{O}$-infected leaves were used as the negative control. Indigo-blue staining indicates increased GUS activity of the rocF promoter. B, GUS activity determination of the PXO99A strains with or without the pSS122 plasmid containing the $r o c F$ promoter under the XVM1 medium with or without $0.1 \mathrm{mM}$ of arginine and X-Gluc. Indigo staining indicates increased activity of the $r o c F$ promoter. The experiment was repeated three times. XVM1 = XVM1 without $0.1 \mathrm{mM}$ of arginine and XVM1 ${ }^{\#}=\mathrm{XVM} 1$ with $0.1 \mathrm{mM}$ of arginine. 
Deletion of $\operatorname{rocF}$ reduces EPS production by $X$. oryzae pv. oryzae. EPS formation is associated with attachment to different environmental surfaces and EPS represents an essential factor in the virulence of pathogenic bacteria (Neo et al. 2010). This finding promoted us to determine whether the deletion of rocF affects EPS production in PXO99A. The wild-type, $\Delta r o c F$, and $\Delta \operatorname{roc} F(\operatorname{roc} F)$ strains were grown in NB liquid medium for 5 days, and EPS was extracted from the cultures and quantified as described in the Materials and Methods. The results showed that EPS production was reduced by approximately $50 \%$ in the $\Delta r o c F$ strain compared with the wild-type strain and there was no significant difference in EPS production between the $\Delta \operatorname{roc} F(\operatorname{roc} F)$ strain and wild-type strain (Fig. 5A). In addition, our qRT-PCR data showed that deletion of $r o c F$ caused significantly decreased expression of genes related to the polysaccharide biosynthesis process, including PXO_RS15910 (GumC), PXO_RS14800 ( $\alpha$-L-fucosidase), PXO_ RS11405 (sugar ABC transporter permease), PXO_RS11410 (multiple sugar transport system substrate-binding protein), $P X O_{-}$ RS08055 (L-arabinonolactonase), PXO_RS10635 (multiple sugar transport system ATP-binding protein), and PXO_RS14820 (glycoside hydrolase family 3 ) (Fig. 5B). These data demonstrate that rocF plays an important role in the EPS production of PXO99A.

Loss of $\operatorname{rocF}$ affects the biofilm formation of $X$. oryzae pv. oryzae on abiotic surfaces. EPS is involved in the formation of biofilm, which is a virulence factor in many plant-pathogenic
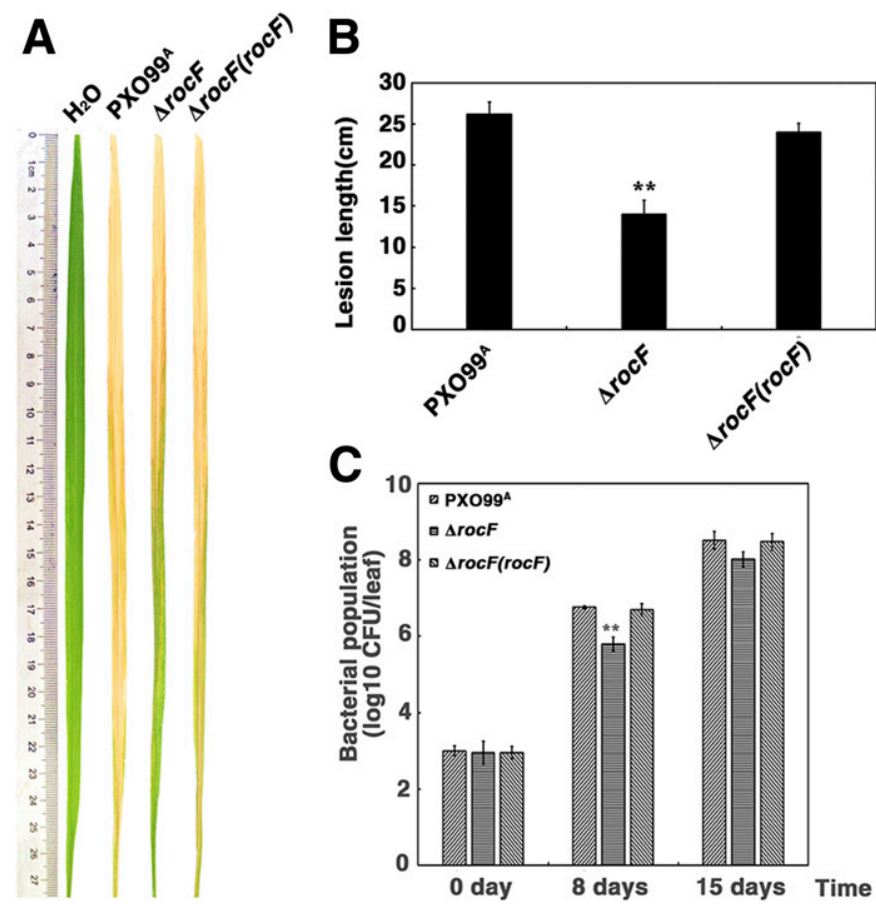

Fig. 4. Results of the pathogenicity test of Xanthomonas oryzae pv. oryzae on host rice. A, Disease symptoms caused by the wild-type, $\Delta r o c F$, and $\Delta \operatorname{roc} F(\operatorname{roc} F)$ strains on 4- to 5-week-old susceptible rice cultivar IR24 leaves. Representative pictures were taken 15 days postinoculation. Sterilized waterinoculated rice leaves served as a negative control. B, Lesion length caused by the wild-type, $\Delta r o c F$, and $\Delta r o c F(r o c F)$ strains $\left(\mathrm{OD}_{600}=0.5\right)$ on 4- to 5-weekold susceptible rice cultivar IR24 leaves by using a leaf-clipping method. The lesion length was calculated 15 days postinoculation. $\mathbf{C}$, Bacterial populations of the wild-type, $\Delta r o c F$, and $\Delta r o c F(r o c F)$ strains $\left(\mathrm{OD}_{600}=0.5\right)$ on 4- to 5week-old susceptible rice cultivar IR24 leaves by using a leaf-clipping method. The inoculated rice leaves for extracting bacteria were harvested after 0,8 , and 15 days, homogenized in sterilized water, and serially diluted on nutrient broth solid plates to count the number of bacterial populations (in CFU). The bacterial populations were presented as the log CFU per leaf. Values are the means \pm SD from three independent experiments $(n=50)$. Asterisks above the error bars indicate significant differences compared with the wild-type strain ( $t$ test, $\left.{ }^{* *} P<0.01\right) . \Delta \operatorname{roc} F=\operatorname{roc} F$ deletion mutant strain, $\Delta \operatorname{roc} F(\operatorname{roc} F)=$ complementary strain, and $\mathrm{OD}_{600}=$ optical density at $600 \mathrm{~nm}$. bacteria (Danhorn and Fuqua 2007; Vu et al. 2009). Because the deletion of rocF reduced EPS production, it is likely that $r o c F$ is related to the biofilm formation in PXO99A. To test this hypothesis, we determined biofilm formation in the wild-type, $\triangle \operatorname{roc} F$, and $\Delta \operatorname{roc} F(r o c F)$ strains of $\mathrm{PXO} 99^{\mathrm{A}}$ on the surface of polystyrene tubes. The results showed that biofilm formation on the polystyrene tube surface by the $\triangle r o c F$ strain was significantly reduced compared with that formed by the wild-type strain (Fig. 6A). The level of crystal violet staining, which indicates biofilm formation, in the $\triangle$ rocF strain was reduced by approximately $40 \%$ compared with that produced by the wild-type strain (Fig. 6B); crystal violet staining of biofilm produced by the complemented strain was restored to the level observed for the wild-type strain. These results indicate that $\mathrm{rocF}$ contributes to the biofilm formation of PXO99A on the surface of polystyrene tubes. To further validate these results, we used CLSM technology to observe the biofilm formation of PXO99A strains as described in the Materials and Methods. The results showed that the $\triangle r o c F$ strain produced a less organized biofilm than the wild-type strain. At the same time, the biofilm thickness produced by the $\Delta r o c F$ strain was approximately 20 to $30 \mu \mathrm{m}$, which was much thinner than the approximately 50 - to 60$\mu \mathrm{m}$-thick biofilm produced by the wild-type strain (Fig. $6 \mathrm{C}$ ). These data indicate that the deletion of $r o c F$ negatively influenced biofilm formation. Therefore, the data from these two assays demonstrate that $r o c F$ is required for biofilm formation of $\mathrm{PXO} 99 \mathrm{~A}$.

rocF contributes to the $\mathrm{H}_{2} \mathrm{O}_{2}$ stress tolerance of $X$. oryzae pv. oryzae. During infection, plant bacterial pathogens produce EPS and biofilm to protect them against the damage caused by environmental stresses such as $\mathrm{H}_{2} \mathrm{O}_{2}$ (Vu et al. 2009). Therefore, we carried out the experiments as described in the Materials and Methods to investigate the role of rocF in resistance to $\mathrm{H}_{2} \mathrm{O}_{2}$. The results showed that the growth of the $\triangle \operatorname{roc} F$ strain was weaker on 0.1 - and $0.2-\mathrm{mM} \mathrm{H}_{2} \mathrm{O}_{2}$ plates than the growth of the wild-type strain (Fig. 7A). A similar result was found in $8 \mathrm{ml}$ of NB liquid medium with $0,0.1$, and $0.2 \mathrm{mM}$ of $\mathrm{H}_{2} \mathrm{O}_{2}$ (Fig. 7B). In addition, the growth rate of the $\triangle \mathrm{rocF}$ strain was significantly inhibited in the presence of $0.2 \mathrm{mM}$ of $\mathrm{H}_{2} \mathrm{O}_{2}$ in NB liquid medium compared with the wild-type and $\triangle \operatorname{roc} F(\operatorname{rocF})$ strains (Fig. 7C). All of the results indicated that the $\triangle r o c F$ strain was significantly more sensitive to $\mathrm{H}_{2} \mathrm{O}_{2}$ than the wild-type strain. In addition, the complementary strain could fully rescue their tolerance to $\mathrm{H}_{2} \mathrm{O}_{2}$. At the same time, genes involved in $\mathrm{H}_{2} \mathrm{O}_{2}$ detoxification and adaptation, including PXO_RS17325 (catalase HPII), PXO_RS22555 (catalase), PXO_RSO5475 (ahpC), $P X O \_R S 05465$ (LysR family transcription regulator), and $P X O_{-}$ RSO6520 (Fur family transcription regulator), were measured. Their transcription levels were determined by qRT-PCR in the wildtype strain and the $\triangle r o c F$ strain in the presence of $0.1 \mathrm{mM}$ of $\mathrm{H}_{2} \mathrm{O}_{2}$. The results showed that the expression of these genes was significantly reduced in the $\triangle \operatorname{roc} F$ strain compared with that in the wild-type strain (Fig. 7D). Taken together, these data demonstrate that rocF is indeed involved in the $\mathrm{H}_{2} \mathrm{O}_{2}$ stress tolerance of PXO99A.

\section{DISCUSSION}

In this study, we identified a novel $X$. oryzae pv. oryzae virulence gene, $\operatorname{roc} F$, which encodes arginase. A rocF mutant showed dramatically reduced virulence on rice. The results of this study indicate that decreased EPS production, reduced biofilm formation, and enhanced $\mathrm{H}_{2} \mathrm{O}_{2}$ sensitivity are major reasons for the deficiency in virulence of the $r o c F$ mutant.

EPS is an important virulence determinant in Xanthomonas spp. during the infection of pathogens. EPS can create an environment for the growth and spread of pathogens in planta and can protect pathogens against toxic compounds from hosts to enhance pathogenicity (e.g., $\mathrm{H}_{2} \mathrm{O}_{2}$ ) (Guo et al. 2015). The detR mutant showed reduced virulence of $X$. oryzae pv. oryzae, which resulted from a reduction of EPS and intolerance to ROS (Nguyen et al. 
2016). Deletion of rocF in $X$. oryzae pv. oryzae also resulted in the loss of EPS production; at the same time, the transcription level of $P X O \_R S 15910$ (gumC) was decreased in $\Delta r o c F$ compared with the wild type. GumC is one of the important gum genes that is responsible for transport and polymerization and is required for EPS synthesis; mutation of this gene showed reduced virulence (Kim et al. 2009). Therefore, we conclude that $r o c F$ plays an important role in EPS biosynthesis and virulence by regulating gumC transcription. Another key factor contributing to the loss of virulence of the rocF mutant is reduced biofilm formation. $X$. oryzae pv. oryzae can adhere to the plant surface and then invade the intercellular space of the host plant cells to acquire nutrition and impair plant defense responses. Biofilm is potentially associated with adhesion to surfaces during infection and colonization and is important for tolerance to environmental stresses of X. oryzae pv. oryzae (Boher et al. 1997; Crossman and Dow 2004; Vu et al. 2009). Our results showed that the deletion of roc $F$ caused less formation of biofilm on the surface of polystyrene tubes. Therefore, we conclude that $r o c F$ is crucial for the formation of biofilm to regulate the virulence of $X$. oryzae pv. oryzae. X. oryzae pv. oryzae successfully infects rice depending on the ability to counteract $\mathrm{H}_{2} \mathrm{O}_{2}$, and its catalases are essential for the detoxification process of $\mathrm{H}_{2} \mathrm{O}_{2}$. Yu et al. (2016) reported that the OxyR regulated catalase $\mathrm{CatB}$ functions as an important factor to detoxify $\mathrm{H}_{2} \mathrm{O}_{2}$ in order to promote the bacterial pathogenesis of $X$. oryzae $\mathrm{pv}$. oryzae on rice. In our study, $\Delta r o c F$ was hypersensitive to $\mathrm{H}_{2} \mathrm{O}_{2}$ and a very small bacterial population survived under the condition of $0.2 \mathrm{mM}$ of $\mathrm{H}_{2} \mathrm{O}_{2}$. In addition, we measured the transcription levels of catalases in $\triangle r o c F$ because catalase is required for the detoxification of $\mathrm{H}_{2} \mathrm{O}_{2}$ in Xanthomonas spp. during their early stages of infection. qRT-PCR results indicated that the transcription levels of $P X O \_R S 17325$ (catalase HPII), PXO_RS22555 (catalase), and $P X O \_R S 05475(a h p C)$ were deregulated. These findings led us to conclude that the $\operatorname{rocF}$ mutant caused dramatically reduced virulence of $X$. oryzae pv. oryzae on rice, maybe owing to the deregulation of detoxifying enzymes such as catalases.

Although EPS production, biofilm formation, and $\mathrm{H}_{2} \mathrm{O}_{2}$ tolerance contribute to the virulence of $X$. oryzae pv. oryzae on rice, more work will be needed to increase our understanding of the underlying molecular mechanisms of their regulation in X. oryzae pv. oryzae. A previous study showed that the metabolic enzyme fructose-1,6- bisphosphate aldolase can combine the promoter region of $k a t G$ and rpoA to regulate their transcription in pathogenic Francisella bacteria (Ziveri et al. 2017). In our study, $r o c F$ encoded arginase, which is an arginine metabolic enzyme, and the transcription levels of genes related to EPS biosynthesis or $\mathrm{H}_{2} \mathrm{O}_{2}$ detoxification were reduced. This led us to conclude that the metabolic enzyme arginase
A

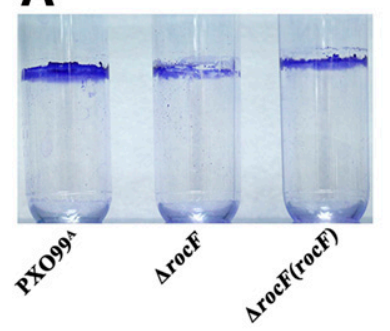

C
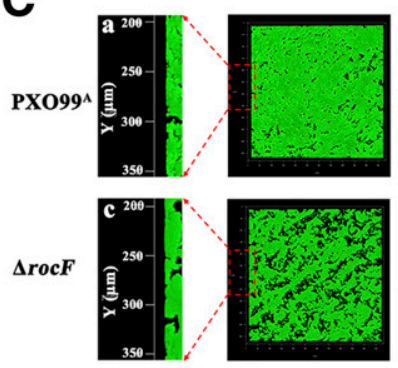

B
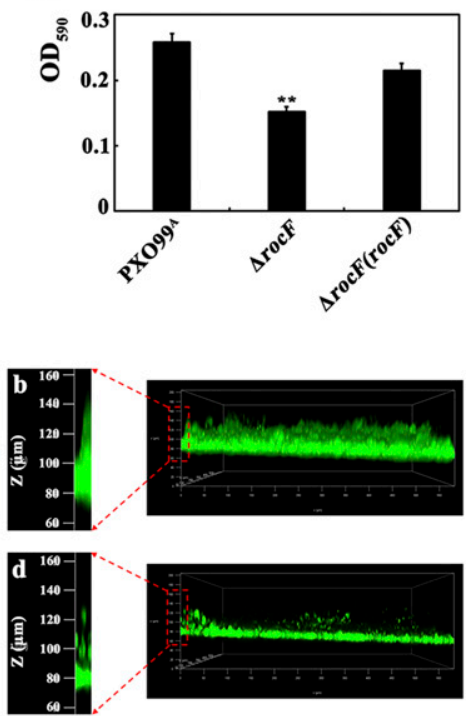

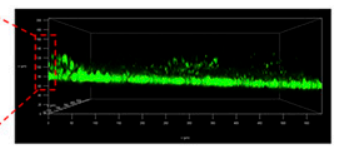

Fig. 6. Effects of rocF deletion on biofilm formation by Xanthomonas oryzae pv. oryzae. A, Biofilm formation by the wild-type, $\Delta \operatorname{rocF}$, and $\Delta \operatorname{rocF}(\operatorname{roc} F)$ strains on polystyrene tubes stained with crystal violet. B, Biofilm production quantification of the wild-type, $\Delta r o c F$, and $\Delta r o c F(r o c F)$ strains on polystyrene tubes corresponding to $\mathrm{A}$. The $\mathrm{OD}_{590}$ value was measured after the stained tubes were incubated with ethanol-acetone. C, Confocal laser scanning microscopy was performed to observe the three-dimensional structure of biofilm formation by the wild-type and $\triangle r o c F$ strains. Images were obtained using a $20 \times$ objective. Values are the means \pm SD from three independent experiments. Asterisks above the error bars indicate significant differences compared with the wild-type $(t$ test, $* * P<0.01) . \Delta r o c F=r o c F$ deletion mutant strain, $\Delta \operatorname{roc} F(\operatorname{roc} F)=$ complementary strain, and $\mathrm{OD}_{590}=$ optical density at $590 \mathrm{~nm}$.
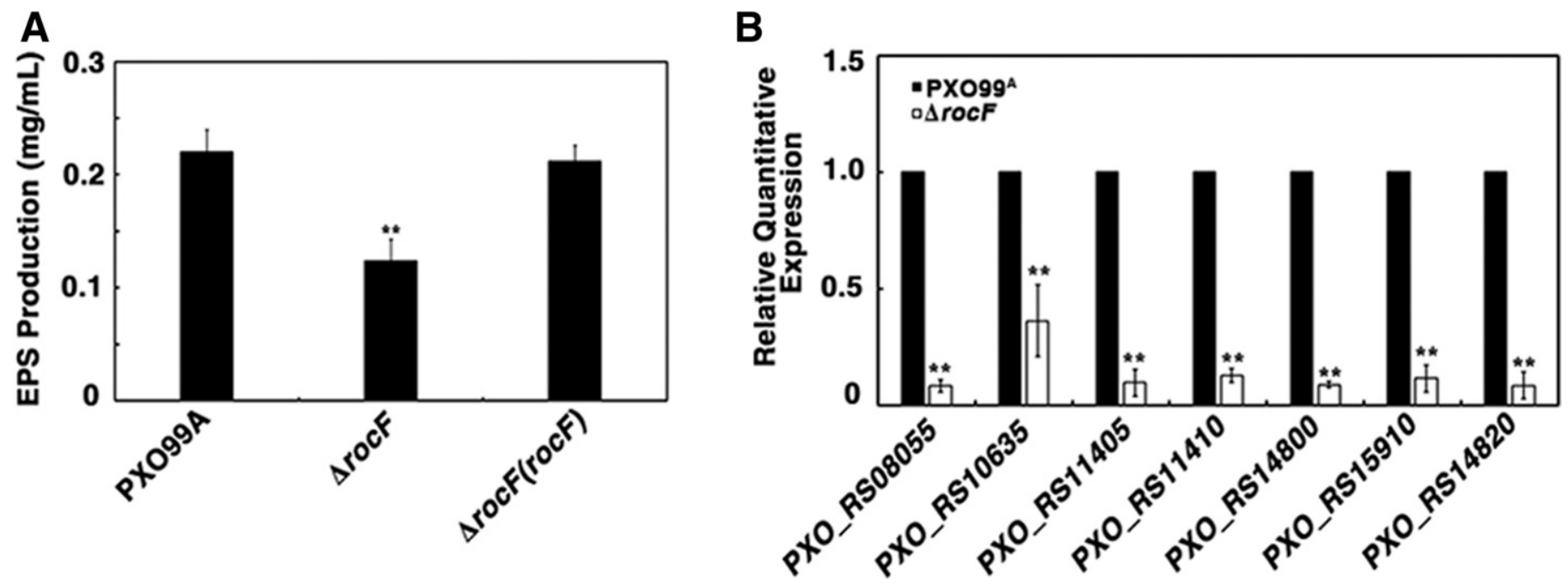

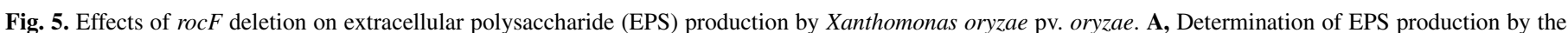

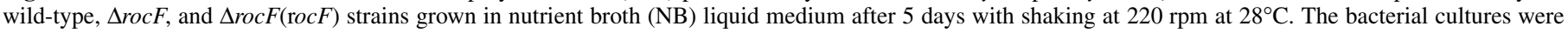

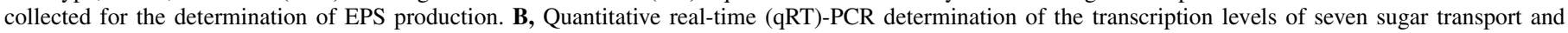

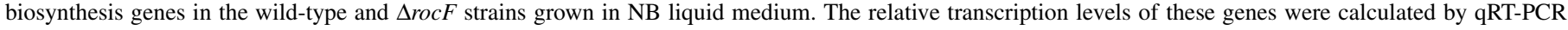

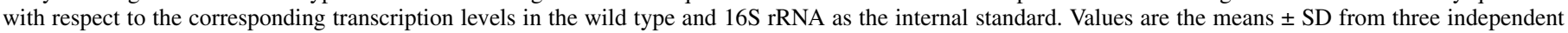

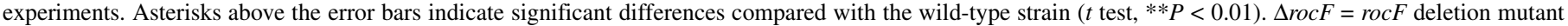
strain and $\Delta \operatorname{roc} F(\operatorname{roc} F)=$ complementary strain. 
A

$\mathrm{H}_{2} \mathrm{O}_{2}(\mathrm{mM} / \mathrm{L})$

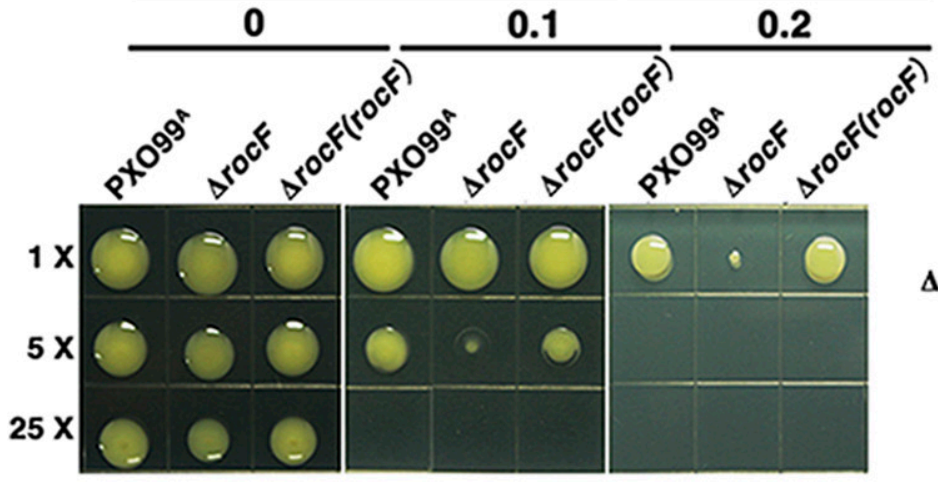

C

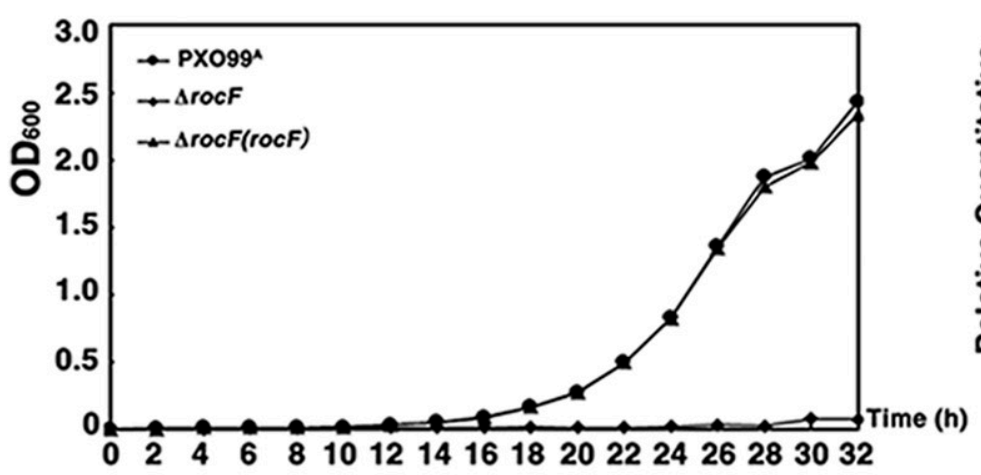

B

$\mathrm{H}_{2} \mathrm{O}_{2}$ (mM/L)

PX099^

$\Delta$ rocF

$\Delta$ rocF(rocF)
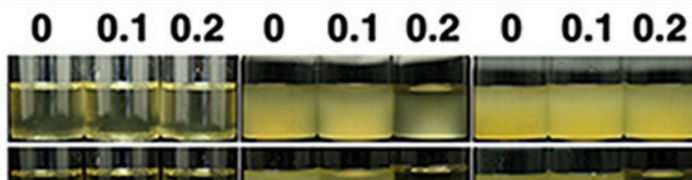

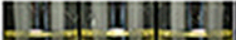

D

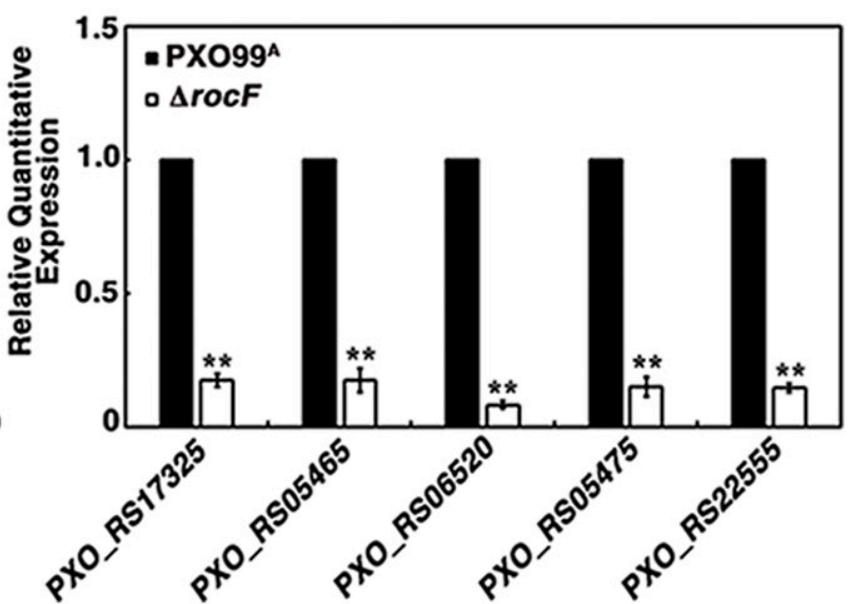

Fig. 7. Observation of Xanthomonas oryzae pv. oryzae resistance to hydrogen peroxide $\left(\mathrm{H}_{2} \mathrm{O}_{2}\right)$. A, The wild-type, $\Delta \operatorname{roc} F$, and $\Delta \operatorname{roc} F(\operatorname{roc} F)$ strains were precultured to the exponential phase of the indicated value $\left(\mathrm{OD}_{600}=1.0\right)$ in nutrient broth $(\mathrm{NB})$ liquid medium as the initial cultures $(1 \times)$, which were then diluted 5 -fold $(5 \times)$ and 25-fold (25x). Three-microliter suspensions of the initial cultures and diluted cultures for each strain were dropped onto NB solid medium plates with 0 , 0.1 , and $0.2 \mathrm{mM}$ of $\mathrm{H}_{2} \mathrm{O}_{2}$ to observe their growth defects. B, Eight-microliter suspensions of the initial cultures in A were transformed into $8 \mathrm{ml}$ of NB liquid medium with $0,0.1$, and $0.2 \mathrm{mM}$ of $\mathrm{H}_{2} \mathrm{O}_{2}$ to observe their growth defects. Pictures were taken of each sample at 0 , 24, and 48 h. C, Twenty-microliter suspensions of the initial cultures in A were transformed into $20 \mathrm{ml}$ of NB liquid medium with $0.2 \mathrm{mM}$ of $\mathrm{H}_{2} \mathrm{O}_{2}$ to observe their growth rates. The value of each sample at $\mathrm{OD}_{600}$ was measured every $2 \mathrm{~h}$. D, mRNA expression levels of genes associated with detoxification and adaptation to $\mathrm{H}_{2} \mathrm{O}_{2}$ in the wild-type and $\Delta$ rocF strains grown in NB liquid medium with $0.1 \mathrm{mM}$ of $\mathrm{H}_{2} \mathrm{O}_{2}$ were determined using quantitative real-time (qRT)-PCR. Relative transcription levels of these genes were calculated by qRTPCR with respect to the corresponding transcription levels in the wild type and 16S rRNA as the internal standard. Values are the means \pm SD from three independent experiments. Asterisks above the error bars indicate significant differences compared with the wild-type strain $(t$ test, $* * P<0.01)$. $\Delta$ roc $F=\operatorname{roc} F$ deletion mutant strain, $\triangle \operatorname{roc} F(\operatorname{roc} F)=$ complementary strain, and $\mathrm{OD}_{600}=$ optical density at $600 \mathrm{~nm}$

can also possibly combine the promoter region of these genes to regulate their transcription.

Arginine has also been characterized as an important nitrogen source for plants (Slocum 2005). More importantly, arginine is a common substrate used by NOS to produce NO, and NO is a diffusible molecular messenger that plays a key role in the rapid induction of the plant immune response (Vidhyasekaran 2014). Whether the rocF mutant caused dramatically reduced virulence of $X$. oryzae pv. oryzae on rice is associated with the metabolic of arginine then inhibit the NO production of rice requires further study.

In summary, this study demonstrated that after $X$. oryzae pv. oryzae infects rice, the arginine in rice is used by $X$. oryzae pv. oryzae to induce rocF expression, which contributes to EPS production, biofilm formation, and $\mathrm{H}_{2} \mathrm{O}_{2}$ detoxification. Notably, all of these functions are major factors that contribute to the reduced virulence of the $\operatorname{roc} F$ deletion mutant strain. To our knowledge, this is the first report of a bacterial arginase that is a functional virulence factor in a plant pathogen. This study not only identified a conserved protein, RocF, as a virulence determinant in X. oryzae pv. oryzae, but it is also helpful to our understanding of the pathogenic mechanisms of $X$. oryzae pv. oryzae. In future studies, it will be interesting to determine how rocF contributes to the expression of important genes in EPS production and $\mathrm{H}_{2} \mathrm{O}_{2}$ detoxification and adaptation.

\section{LITERATURE CITED}

Andrade, M. O., Farah, C. S., and Wang, N. 2014. The post-transcriptional regulator $\mathrm{rsmA} / \mathrm{csrA}$ activates T3SS by stabilizing the $5^{\prime} \mathrm{UTR}$ of hrpG, the master regulator of hrp/hrc genes, in Xanthomonas. PLoS Pathog 10: e1003945.

Bae, N., Park, H. J., Park, H., Kim, M., and Han, S. W. 2018. Deciphering the functions of the outer membrane porin OprBXo involved in virulence, motility, exopolysaccharide production, biofilm formation and stress tolerance in Xanthomonas oryzae pv. oryzae. Mol. Plant Pathol. 19:2527-2542.

Boher, B., Nicole, M., Potin, M., and Geiger, J. P. 1997. Extracellular polysaccharides from Xanthomonas axonopodis pv. manihotis interact with cassava cell walls during pathogenesis. Mol. Plant-Microbe Interact. 10: 803-811.

Boitz, J. M., Gilroy, C. A., Olenyik, T. D., Paradis, D., Perdeh, J., Dearman, K., Davis, M. J., Yates, P. A., Li, Y., and Riscoe, M. K. 2017. Arginase is essential for survival of Leishmania donovani promastigotes but not intracellular amastigotes. Infect. Immun. 85:e00554-16. 
Brown, D. G., Swanson, J. K., and Allen, C. 2007. Two host-induced Ralstonia solanacearum genes, acrA and dinF, encode multidrug efflux pumps and contribute to bacterial wilt virulence. Appl. Environ. Microbiol. 73:2777-2786.

Bumann, D., and Valdivia, R. H. 2007. Identification of host-induced pathogen genes by differential fluorescence induction reporter systems. Nat. Protoc. 2:770-777.

Büttner, D., and Bonas, U. 2010. Regulation and secretion of Xanthomonas virulence factors. FEMS Microbiol. Rev. 34:107-133.

Calogero, S., Gardan, R., Glaser, P., Schweizer, J., Rapoport, G., and Debarbouille, M. 1994. RocR, a novel regulatory protein controlling arginine utilization in Bacillus subtilis, belongs to the NtrC/NifA family of transcriptional activators. J. Bacteriol. 176:1234-1241.

Crossman, L., and Dow, J. M. 2004. Biofilm formation and dispersal in Xanthomonas campestris. Microbes Infect. 6:623-629.

Danhorn, T., and Fuqua, C. 2007. Biofilm formation by plant-associated bacteria. Annu. Rev. Microbiol. 61:401-422.

Gardan, R., Rapoport, G., and Débarbouillé, M. 1995. Expression of the rocDEF operon involved in arginine catabolism in Bacillus subtilis. J. Mol. Biol. 249:843-856.

George, G., Kombrabail, M., Raninga, N., and Sau, A. K. 2017. Arginase of Helicobacter gastric pathogens uses a unique set of non-catalytic residues for catalysis. Biophys. J. 112:1120-1134.

Gobert, A. P., McGee, D. J., Akhtar, M., Mendz, G. L., Newton, J. C., Cheng, Y., Mobley, H. L., and Wilson, K. T. 2001. Helicobacter pylori arginase inhibits nitric oxide production by eukaryotic cells: A strategy for bacterial survival. Proc. Natl. Acad. Sci. USA 98:13844-13849.

González, J. F., Degrassi, G., Devescovi, G., De Vleesschauwer, D., Hofte, M., Myers, M. P., and Venturi, V. 2012. A proteomic study of Xanthomonas oryzae pv. oryzae in rice xylem sap. J. Proteomics 75:5911-5919.

González, J. F., Myers, M. P., and Venturi, V. 2013. The inter-kingdom solo OryR regulator of Xanthomonas oryzae is important for motility. Mol. Plant Pathol. 14:211-221.

Guo, W., Zou, L. F., Cai, L. L., and Chen, G. Y. 2015. Glucose-6-phosphate dehydrogenase is required for extracellular polysaccharide production, cell motility and the full virulence of Xanthomonas oryzae pv. oryzicola. Microb. Pathog. 78:87-94.

Hilaire, E., Young, S. A., Willard, L. H., McGee, J. D., Sweat, T., Chittoor, J. M., Guikema, J. A., and Leach, J. E. 2001. Vascular defense responses in rice: Peroxidase accumulation in xylem parenchyma cells and xylem wall thickening. Mol. Plant-Microbe Interact. 14:1411-1419.

Jakubovics, N. S., Robinson, J. C., Samarian, D. S., Kolderman, E., Yassin, S. A., Bettampadi, D., Bashton, M., and Rickard, A. H. 2015. Critical roles of arginine in growth and biofilm development by Streptococcus gordonii. Mol. Microbiol. 97:281-300.

Kachroo, P., Lee, K. H., Schwerdel, C., Bailey, J. E., and Chattoo, B. B. 1997. Analysis of host-induced response in the rice blast fungus Magnaporthe grisea using two-dimensional polyacrylamide gel electrophoresis. Electrophoresis 18:163-169.

Kim, S. Y., Kim, J. G., Lee, B. M., and Cho, J. Y. 2009. Mutational analysis of the gum gene cluster required for xanthan biosynthesis in Xanthomonas oryzae pv oryzae. Biotechnol. Lett. 31:265-270.

Li, J., and Wang, N. 2012. The gpsX gene encoding a glycosyltransferase is important for polysaccharide production and required for full virulence in Xanthomonas citri subsp. citri. BMC Microbiol. 12:31.

Lu, C. D. 2006. Pathways and regulation of bacterial arginine metabolism and perspectives for obtaining arginine overproducing strains. Appl. Microbiol. Biotechnol. 70:261-272.

Marquis, R. E. 1995. Oxygen metabolism, oxidative stress and acid-base physiology of dental plaque biofilms. J. Ind. Microbiol. 15:198-207.

Neo, Y. L., Li, R., Howe, J., Hoo, R., Pant, A., Ho, S. Y., and Alonso, S. 2010. Evidence for an intact polysaccharide capsule in Bordetella pertussis. Microbes Infection 12:238-245.

Nguyen, M. P., Park, J., Cho, M. H., and Lee, S. W. 2016. Role of DetR in defence is critical for virulence of Xanthomonas oryzae pv. oryzae. Mol. Plant Pathol. 17:601-613.

Niño-Liu, D. O., Ronald, P. C., and Bogdanove, A. J. 2006. Xanthomonas oryzae pathovars: Model pathogens of a model crop. Mol. Plant Pathol. 7:303-324.
Padalon-Brauch, G., Hershberg, R., Elgrably-Weiss, M., Baruch, K., Rosenshine, I., Margalit, H., and Altuvia, S. 2008. Small RNAs encoded within genetic islands of Salmonella typhimurium show host-induced expression and role in virulence. Nucleic Acids Res. 36:1913-1927.

Pandey, A., and Sonti, R. V. 2010. Role of the FeoB protein and siderophore in promoting virulence of Xanthomonas oryzae pv. oryzae on rice. J. Bacteriol. 192:3187-3203.

Qian, G. L., Liu, C. H., Wu, G. C., Yin, F. Q., Zhao, Y. C., Zhou, Y. J., Zhang, Y. B., Song, Z. W., Fan, J. Q., Hu, B. S., and Liu, F. Q. 2013. AsnB, regulated by diffusible signal factor and global regulator Clp, is involved in aspartate metabolism, resistance to oxidative stress and virulence in Xanthomonas oryzae pv. oryzicola. Mol. Plant Pathol. 14:145-157.

Sere, Y., Onasanya, A., Verdier, V., Akator, K., Ouedraogo, L. S., Segda, Z., Mbare, M. M., Sido, A. Y., and Basso, A. 2005. Rice bacterial leaf blight in West Africa: Preliminary studies on disease in farmers' fields and screening released varieties for resistance to the bacteria. Asian J. Plant Sci. 4:577-579.

Shi, Y. Y., Chen, M., Zhang, Y. X., Zhang, J., and Ding, S. G. 2014. Expression of three essential antioxidants of Helicobacter pylori in clinical isolates. J. Zhejiang Univ. Sci. B 15:500-506.

Slocum, R. D. 2005. Genes, enzymes and regulation of arginine biosynthesis in plants. Plant Physiol. Biochem. 43:729-745.

Song, Z., Zhao, Y., Qian, G., Odhiambo, B. O., and Liu, F. 2017. Novel insights into the regulatory roles of gene hshB in Xanthomonas oryzae pv. oryzicola. Res. Microbiol. 168:165-173.

Sutherland, I. W. 1988. Bacterial surface polysaccharides: Structure and function. Int. Rev. Cytol. 113:187-231.

Tondo, M. L., Delprato, M. L., Kraiselburd, I., Zenoff, M. V. F., Farias, M. E., and Orellano, E. G. 2016. KatG, the bifunctional catalase of Xanthomonas citri subsp citri, responds to hydrogen peroxide and contributes to epiphytic survival on citrus leaves. PLoS One 11:e0151657.

Tsuge, S., Furutani, A., Fukunaka, R., Oku, T., Tsuno, K., Ochiai, H., Inoue, Y., Kaku, H., and Kubo, Y. 2002. Expression of Xanthomonas oryzae pv. oryzae hrp genes in XOM2, a novel synthetic medium. J. Gen. Plant Pathol. 68:363-371.

Vidhyasekaran, P. 2014. Phospholipids signaling system in plant innate immunity. Nitric Oxide Signal Syst. Plant Innate Immun. 21:375-384.

Von Bodman, S. B., Majerczak, D. R., and Coplin, D. L. 1998. A negative regulator mediates quorum-sensing control of exopolysaccharide production in Pantoea stewartii subsp. stewartii. Proc. Natl. Acad. Sci. U.S.A. 95:7687-7692.

Vu, B., Chen, M., Crawford, R. J., and Ivanova, E. P. 2009. Bacterial extracellular polysaccharides involved in biofilm formation. Molecules 14: 2535-2554.

Wang, B., Wu, G., Zhang, Y., Qian, G., and Liu, F. 2018. Dissecting the virulence-related functionality and cellular transcription mechanism of a conserved hypothetical protein in Xanthomonas oryzae pv. oryzae. Mol. Plant Pathol. 19:1859-1872.

Xiong, L., Teng, J. L. L., Botelho, M. G., Lo, R. C., Lau, S. K. P., and Woo, P. C. Y. 2016. Arginine metabolism in bacterial pathogenesis and cancer therapy. Int. J. Mol. Sci. 17:363.

Yu, C., Wang, N., Wu, M., Tian, F., Chen, H., Yang, F., Yuan, X., Yang, C. H., and He, C. 2016. OxyR-regulated catalase CatB promotes the virulence in rice via detoxifying hydrogen peroxide in Xanthomonas oryzae pv. oryzae. BMC Microbiol. 16:269.

Zabaleta, J., McGee, D. J., Zea, A. H., Hernandez, C. P., Rodriguez, P. C., Sierra, R. A., Correa, P., and Ochoa, A. C. 2004. Helicobacter pylori arginase inhibits $\mathrm{T}$ cell proliferation and reduces the expression of the TCR zeta-chain (CD3zeta). J. Immunol. 173:586-593.

Zhu, Y., Weiss, E. C., Otto, M., Fey, P. D., Smeltzer, M. S., and Somerville, G. A. 2007. Staphylococcus aureus biofilm metabolism and the influence of arginine on polysaccharide intercellular adhesin synthesis, biofilm formation, and pathogenesis. Infect. Immun. 75:4219-4226.

Ziveri, J., Tros, F., Guerrera, I. C., Chhuon, C., Audry, M., Dupuis, M., Barel, M., Korniotis, S., Fillatreau, S., Gales, L., Cahoreau, E., and Charbit, A. 2017. The metabolic enzyme fructose-1,6-bisphosphate aldolase acts as a transcriptional regulator in pathogenic Francisella. Nat. Commun. 8:853. 